Vol 2 No 3 August-October 2019. pp. 1-8. Journal PUBLICUHO Faculty of Social and Political Sciences Halu Oleo University, Kendari, Southeast Sulawesi, Indonesia. ISSN 2621-1351 (online), ISSN 2685-0729 (print) Open Access at:

http://ojs.uho.ac.id/index.php/PUBLICUHO/index

\title{
PERSEPSI PUBLIK LINGKAR INDUSTRI PERTAMBANGAN TERHADAP KEBERADAAN TENAGA KERJA ASING (Studi Kasus PT. Virtue Dragon Nickel Industri, Kecamatan Morosi, Kabupaten Konawe)
}

\author{
${ }^{1}$ La Sampe*, ${ }^{2}$ Irfan Ido, ${ }^{3}$ Jahidin \\ 1,2,3 Fakultas IImu dan Tekonologi Kebumian Universitas Halu Oleo \\ lasampe@gmail.com, irfanido@uho.ac.id
}

\begin{abstract}
This study aims to determine the public perception of the characteristics of foreign workers, that is a lifestyle, relationships and attitudes, by using estimator errors of $10 \%$, a total of samples is 60 heads of families in Morosi village. The results of this study indicate that public perceptions of the lifestyle of foreign workers as much as $73.33 \%$ of respondents stated good, as many as $25.00 \%$ stated is less good, as much as $1.67 \%$ stated is not good. Public perceptions of the interaction of foreign workers as much as $53.33 \%$ of respondents stated is less good, as many as $36.67 \%$ stated is good, as many as $8.33 \%$ of respondents stated is not good, as much as $1.67 \%$ of respondents stated is very good. Public perceptions of the attitude of foreign workers as much as $53.33 \%$ of respondents stated is less good and as many as $46.67 \%$ of respondents stated is good.
\end{abstract}

Keywords: Foreign Workers; Mining; Public Perception

\begin{abstract}
Abstrak
Penelitian ini bertujuan untuk mengetahui persepsi publik tentang karakteristik pekerja asing, yaitu gaya hidup, hubungan dan sikap, dengan menggunakan kesalahan penduga sebesar 10\%, total sampel adalah 60 kepala keluarga di desa Morosi. Hasil penelitian ini menunjukkan bahwa persepsi masyarakat terhadap gaya hidup pekerja asing sebanyak $73,33 \%$ responden menyatakan baik, sebanyak 25,00\% menyatakan kurang baik, sebanyak $1,67 \%$ menyatakan tidak baik. Persepsi publik tentang interaksi pekerja asing sebanyak 53,33\% responden menyatakan kurang baik, sebanyak $36,67 \%$ menyatakan baik, sebanyak $8,33 \%$ responden menyatakan tidak baik, sebanyak $1,67 \%$ responden menyatakan tidak baik. sangat bagus. Persepsi publik terhadap sikap pekerja asing sebanyak 53,33\% responden menyatakan kurang baik dan sebanyak $46,67 \%$ responden menyatakan baik.
\end{abstract}

Kata kunci: Persepsi Publik; Pertambangan; Tenaga Kerja Asing

\section{PENDAHULUAN}

Menurut kementerian ESDM (2018) fasilitas pengolahan dan pemurnian atau smelter yang telah beroperasi di Indonesi sampai akhir tahun 2017 sebanyak 24 unit, yang terdiri dari smelter nikel sebanyak 15 unit, smelter besi 4 unit, smelter bauksit 2 unit, smelter mangan 2 unit dan smelter tembaga 1 unit. Salah satu smelter nikel yang telah beroperasi hingga saat ini adalah PT. Virtue Dragon Industry yang terletak di desa Morosi Kec. Morosi, Kab. Konawe. PT. VDNI memiliki tenaga kerja asing sebanyak 632 orang dan merupakan TKA dari Tiongkok. Tenaga kerja asing tersebut tinggal tidak jauh dari lokasi PT. VDNI berada. Adanya tenaga kerja asing yang bekerja dan tinggal disekitar perusahaan, mengakibatkan adanya interaksi antara tenaga kerja asing dengan Publik lingkar industri pertambangan, interaksi tersebut dapat terjadi ketika tenaga kerja asing melakukan istirahat pada siang hari, saat belanja kebutuhan sehari-hari di warung-warung milik Publik setempat dan acara-acara pesta perkawinan atau kegiatan lainnya yang diadakan di desa Morosi. Dengan adanya interaksi 
tersebut, dapat menimbulkan presepsi Publik lingkar industri pertambangan terhadap karateristik pekerja tenaga kerja asing PT. VDNI. Persepsi merupakan proses penilaian seseorang terhadap objek tertentu. Penilaian itu akan muncul jika seseorang memiliki perhatian pada sebuah objek (Rahmat, 2012). Sehingga, perlu dilakukan penelitian mengenai Persepsi Publik lingkar industri pertambangan terhadap karateristik pekerja tenaga kerja asing PT. Virtue Dragon Nickel Industri. Penelitian ini bertujuan untuk mengetahui Persepsi Publik lingkar industri pertambangan terhadap karateristik pekerja tenaga kerja asing PT. Virtue Dragon Nikel Industri di Industri di Kecamatan Morosi Kabupaten Konawe, dan dapat menjadi masukan bagi perusahaan dalam merekrut tenaga kerja dan bagi pemerintah dalam membuat dan menerapkan peraturan tentang tenaga kerja asing.

\section{METODE PENELITIAN}

\section{Jenis Penelitian}

Pendekatan penelitian ini menggunakan pendekatan kuantitatif. Metode pendekatan kuantitatif adalah penelitian dengan memperoleh data yang berbentuk angka atau data kualitatif yang berupa angka-angka kemudian dijelaskan secara baik (Sugiyono, 2014).

Penelitian ini dilakukan di lingkar industri PT. Virtue Dragon Nickel Industri Kecamatan Morosi Kabupaten Konawe Provinsi Sulawesi Tenggara.

\section{Informan Penelitian}

Jumlah Kepala Keluarga disekitar lingkar tambang Desa Morosi sebanyak 153 kepala keluarga, Jumlah sampel ditentukan dengan mengunakan metode slovin (Usman dan Abdi. 2008), dengan menggunakan rumus :

$\mathrm{n}=\frac{\mathrm{N}}{1+\mathrm{N}(\mathrm{e})^{2}}$

Keterangan :

$\mathrm{n}=$ Jumlah sampel

$\mathrm{N}=$ Jumlah populasi

$\mathrm{e}=$ Galat penduga

Galat penduga yang digunakan sebesar 10\%, dan didapatkan jumlah sampel sebanyak 60 kepala keluarga

\section{Teknik Analisis Data}

Teknik analisis data pada penelitian ini menggunakan teknik analisis deskripti kuantitatif, dengan menggunakan bobot pada Tabel 1.

Tabel 1. Kategori Penilaian Skala Likert (Sumber : Sugiono, 2010)

\begin{tabular}{lcc}
\hline \multirow{2}{*}{ Kategori } & \multicolumn{2}{c}{ Bobot Pernyataan } \\
\cline { 2 - 3 } & Positif & Negarif \\
\hline Sangat Baik & 5 & 1 \\
\hline Baik & 4 & 2 \\
\hline Ragu-ragu & 3 & 3 \\
\hline Tidak Baik & 2 & 4 \\
\hline Sangat Tidak Baik & 1 & 5 \\
\hline
\end{tabular}

Untuk mengukur pendapat atau presepsi Publik tentang Gaya Hidup, Pergaulan dan Sikap Perilaku, maka digunakan rumus interval yaitu sebagai berikut:

$$
\mathrm{i}=\frac{\mathrm{J}}{\mathrm{K}}
$$

Keterangan :

I = Interval kelas

$\mathrm{J}=$ Jarak sebaran (skor tinggi-skor rendah)

$\mathrm{K}=$ Banyaknya kelas

Didapatkan interval kelas sebesar 2,4, ntuk kriteria peniliaian persepsi, dapat dilihat pada Tabel 2. 
Vol 2 No 3 August-October 2019. pp. 1-8. Journal PUBLICUHO Faculty of Social and Political Sciences Halu Oleo University, Kendari, Southeast Sulawesi, Indonesia. ISSN 2621-1351 (online), ISSN 2685-0729 (print) Open Access at:

http://ojs.uho.ac.id/index.php/PUBLICUHO/index

Tabel 2. Kriteria penilaian persepsi terhadap karakteristik tenaga kerja asing

\begin{tabular}{ccc}
\hline No. & Kriteria/interval & Persepsi \\
\hline 1. & $3-5,3$ & Sangat tidak baik \\
\hline 2. & $5,4-7,7$ & Tidak baik \\
\hline 3. & $7,8-10,1$ & Ragu-ragu \\
\hline 4. & $10,2-12,5$ & Baik \\
\hline 5. & $12,6-15$ & Sangat Baik \\
\hline
\end{tabular}

kemudian dianalisis dengan menggunakan persentase menurut M. Ali (1985). Maka dapat dirumuskan sebagai berikut :

$P=\frac{f}{n} \times 100$

Keterangan:

$P \quad=$ Persen

$\mathrm{F} \quad \quad=$ Frekuensi jumlah pernyataan jawaban responden

$\mathrm{n} \quad=$ Jumlah responden

$100 \%=$ Bilangan tetap

\section{HASIL DAN PEMBAHASAN}

Persepsi Publik lingkar industri pertambangan terhadap karateristik pekerja tenaga kerja asing di PT. Virtue Dragon Nickel Industri

\section{a. Gaya Hidup Tenaga Kerja Asing di PT. Virtue Dragon Nickel Industri}

Berdasarkan hasil penelitian yang dilakukan tentang persepsi Publik lingkar industri tambang terhadap gaya hidup tenaga kerja asing yang bekerja di PT. VDNI yaitu :

1) Keberadaan tenaga kerja asing di PT. VDNI dapat menimbulkan perubahan konsumsi bagi Publik disekitar lingkar tambang, dapat dilihat pada Tabel 10.

Tabel 3. Persepsi Publik terhadap keberadaan tenaga kerja asing di PT. Virtue Dragon dapat menimbulkan perubahan konsumsi bagi Publik

\begin{tabular}{clcc}
\hline No & Tingkat Jawaban Responden & Jumlah (orang) & $\begin{array}{c}\text { Persentase } \\
\mathbf{( \% )}\end{array}$ \\
\hline 1. & Sangat Setuju & 43 & 71,67 \\
\hline 2. & Setuju & 8 & 13,33 \\
\hline 3. & Ragu-ragu & 4 & 6,67 \\
\hline 4. & Tidak Setuju & 4 & 6,67 \\
\hline 5. & Sangat Tidak Setuju & 1 & 1,66 \\
\hline \multicolumn{2}{c}{ Jumlah } & $\mathbf{6 0}$ & 100 \\
\hline \multicolumn{2}{r}{ Sumber: Data primer diolah (2018) }
\end{tabular}

Berdasarkan Tabel 10. sebanyak $43(71,67 \%)$ responden menyatakan sangat setujuh, sebanyak 8 (13,63\%) menyatakan setuju, sebanyak 4 (6,67\%) menyatakan ragu-ragu, sebanyak 4 (6,67\%) menyatakan tidak setuju, dan 1 (1,66\%) menyatakan sangat tidak setujuh bahwa keberadaan tenaga kerja asing PT. VDNI dapat menimbulkan perubahan konsumsi bagi Publik.

2) Dari segi bahasa para tenaga kerja asing memiliki bahasa tersendiri yang tidak dapat dimengerti oleh Publik di sekitar lingkar tambang, dapat dilihat pada Tabel 4. 
Tabel 4. Persepsi Publik para tenaga kerja asing yang memiliki bahasa tersendiri

\begin{tabular}{clcc}
\hline No & Tingkat Jawaban Responden & Jumlah (orang) & Persentase (\%) \\
\hline 1. & Sangat Setuju & 43 & 71,67 \\
\hline 2. & Setuju & 8 & 13,33 \\
\hline 3. & Ragu-ragu & 4 & 6,67 \\
\hline 4. & Tidak Setuju & 4 & 6,67 \\
\hline 5. & Sangat Tidak Setuju & 1 & 1,66 \\
\hline & Jumlah & $\mathbf{6 0}$ & 100 \\
\hline
\end{tabular}

Sumber: Data primer diolah (2018)

Berdasarkan Tabel 4 . sebanyak $43(71,67 \%)$ responden menyatakan sangat setujuh, sebanyak $8(13,63 \%)$ menyatakan setuju, sebanyak $4(6,67 \%)$ menyatakan ragu-ragu, sebanyak $4(6,67 \%)$ menyatakan tidak setuju, dan $1(1,66 \%)$ menyatakan sangat tidak setujuh, bahwa dari segi bahasa para tenaga kerja asing memiliki bahasa tersendiri yang tidak dapat dimengerti oleh Publik di sekitar lingkar tambang.

3) Para tenaga kerja asing yang ada di PT. Virtue Dragon memiliki gaya hidup yang berlebihan, dapat dilihat pada Tabel 5 .

Tabel 5. Persepsi Publik terhadap para tenaga kerja asing PT. VDNI memiliki gaya hidup yang berlebihan

\begin{tabular}{clcc}
\hline No. & Tingkat Jawaban Responden & Jumlah (orang) & Persentase (\%) \\
\hline 1. & Sangat Setuju & 43 & 71,67 \\
\hline 2. & Setuju & 8 & 13,33 \\
\hline 3. & Ragu-ragu & 4 & 6,67 \\
\hline 4. & Tidak Setuju & 4 & 6,67 \\
\hline 5. & Sangat Tidak Setuju & 1 & 1,66 \\
\hline & & $\mathbf{6 0}$ & 100 \\
\hline
\end{tabular}

Berdasarkan Tabel 5 . sebanyak $43(71,67 \%)$ responden menyatakan sangat setujuh, sebanyak $8(13,63 \%)$ menyatakan setuju, sebanyak $4(6,67 \%)$ menyatakan ragu-ragu, sebanyak $4(6,67 \%)$ menyatakan tidak setuju, dan $1(1,66 \%)$ menyatakan sangat tidak setujuh, bahwa para tenaga kerja asing PT. VDNI memiliki gaya hidup yang berlebihan.

Persepsi Publik terhadap gaya hidup tenaga kerja asing di PT. Virtue Dragon Nickel Industri dapat dilihat pada Tabel 6.

Tabel 6. Persepsi Publik Terhadap Gaya Hidup Tenaga Kerja Asing

\begin{tabular}{clcc}
\hline No. & \multicolumn{1}{c}{ Tingkat Persepsi Publik } & Jumlah (orang) & Persentase (\%) \\
\hline 1. & Sangat Baik & - & - \\
\hline 2. & Baik & 44 & 73,33 \\
\hline 3. & Kurang Baik & 15 & 25,00 \\
\hline 4. & Tidak Baik & 1 & 1,67 \\
\hline 5. & Sangat tidak Baik & - & - \\
\hline \multicolumn{2}{r}{ Jumlah } & $\mathbf{6 0}$ & 100 \\
\hline & Sumber: Data primer diolah (2018)
\end{tabular}

Sebagian besar responden menyatakan tenaga kerja asing yang bekerja di PT. VDNI memiliki pergaulan yang kurang baik. Hal ini dibuktikan bahwa sebanyak 32 (53,33\%) responden menyatakan memiliki pergaulan yang kurang baik, sebanyak $22(36,67 \%)$ memiliki pergaulan yang baik, sebanyak $5(8,33 \%)$ memiliki pergaulan yang tidak baik dan $1(1,67 \%)$ menyatakan memiliki pergaulan yang sangat baik. 
Vol 2 No 3 August-October 2019. pp. 1-8. Journal PUBLICUHO Faculty of Social and Political Sciences Halu Oleo University, Kendari, Southeast Sulawesi, Indonesia. ISSN 2621-1351 (online), ISSN 2685-0729 (print) Open Access at:

http://ojs.uho.ac.id/index.php/PUBLICUHO/index

\section{b. Persepsi Publik Terhadap Pergaulan Tenaga Kerja Asing di PT. Virtue Dragon Nickel Industri}

Berdasarkan hasil penelitian yang dilakukan tentang persepsi Publik lingkar industri tambang terhadap pergaulan tenaga kerja asing di PT. VDNI yaitu :

1. Para tenaga kerja asing selalu menempatkan diri untuk bergaul dengan Publik disekitar lingkar tambang dapat dilihat pada Tabel 7.

Tabel 7. Persepsi Publik terhadap para tenaga kerja asing selalu menempatkan diri untuk bergaul dengan Publik disekitar lingkar tambang

\begin{tabular}{clcc}
\hline No. & \multicolumn{1}{c}{ Tingkat Jawaban Responden } & Jumlah (orang) & Persentase (\%) \\
\hline 1. & Sangat Setuju & 23 & 38,33 \\
\hline 2. & Setuju & 20 & 33,33 \\
\hline 3. & Ragu-ragu & 7 & 11,67 \\
\hline 4. & Tidak Setuju & 5 & 8,33 \\
\hline 5. & Sangat Tidak Setuju & 5 & 8,33 \\
\hline \multicolumn{2}{r}{ Jumlah } & $\mathbf{6 0}$ & $\mathbf{1 0 0}$ \\
\hline & & Sumber: Data primer diolah (2018)
\end{tabular}

Berdasarkan Tabel 7. sebanyak $23(38,33 \%)$ responden menyatakan sangat setujuh, sebanyak $20(33,33 \%)$ menyatakan setuju, sebanyak $7(11,67 \%)$ menyatakan ragu-ragu, sebanyak 4 $(8,33 \%)$ menyatakan tidak setuju, dan 5 (8,33\%) menyatakan sangat tidak setujuh, bahwa para tenaga kerja asing PT. VDNI selalu menempatkan diri untuk bergaul dengan Publik disekitar lingkar tambang

2. Para tenaga kerja asing turut meramaikan kegiatan sosial dilakukan oleh Publik di sekitar lingkar tambang, dapat dilihat pada Tabel 8.

Tabel 8. Persepsi Publik terhadap para tenaga kerja asing ikut turut meramaikan kegiatan sosial yang dilakuakan oleh Publik sekitar lingkar industri tambang

\begin{tabular}{clcc}
\hline No. & \multicolumn{1}{c}{ Tingkat Jawaban Responden } & Jumlah (orang) & Persentase (\%) \\
\hline 1. & Sangat Setuju & 23 & 38,33 \\
\hline 2. & Setuju & 20 & 33,33 \\
\hline 3. & Ragu-ragu & 7 & 11,67 \\
\hline 4. & Tidak Setuju & 5 & 8,33 \\
\hline 5. & Sangat Tidak Setuju & 5 & 8,33 \\
\hline & Jumlah & $\mathbf{6 0}$ & $\mathbf{1 0 0}$ \\
\hline
\end{tabular}

Sumber: Data primer diolah (2018)

Berdasarkan Tabel 8. sebanyak $23(38,33 \%)$ responden menyatakan sangat setujuh, sebanyak $20(33,33 \%)$ menyatakan setuju, sebanyak $7(11,67 \%)$ menyatakan ragu-ragu, sebanyak 4 $(8,33 \%)$ menyatakan tidak setuju, dan $5(8,33 \%)$ menyatakan sangat tidak setuju, bahwa para tenaga kerja asing PT. VDNI ikut turut meramaikan kegiatan sosial yang dilakuakan oleh Publik sekitar lingkar industri tambang

3. Para tenaga kerja asing yang ada di sekitar lingkar tambang tidak pernah bergaul dengan Publik setempat, dapat dilihat pada Tabel 9.

Tabel 9. Persepsi Publik terhadap para tenaga kerja asing yang ada di sekitar lingkar tambang tidak pernah bergaul dengan Publik setempat

\begin{tabular}{clcc}
\hline No. & Tingkat Jawaban Responden & Jumlah (orang) & Persentase (\%) \\
\hline 1. & Sangat Setuju & 23 & 38,33 \\
\hline 2. & Setuju & 20 & 33,33 \\
\hline 3. & Ragu-ragu & 7 & 11,67 \\
\hline 4. & Tidak Setuju & 5 & 8,33 \\
\hline 5. & Sangat Tidak Setuju & 5 & 8,33 \\
\hline & Jumlah & $\mathbf{6 0}$ & $\mathbf{1 0 0}$ \\
\hline
\end{tabular}

Sumber: Data primer diolah (2018) 
Berdasarkan Tabel 9. sebanyak $23(38,33 \%)$ responden menyatakan sangat setujuh, sebanyak $20(33,33 \%)$ menyatakan setuju, sebanyak $7(11,67 \%)$ menyatakan ragu-ragu, sebanyak 4 $(8,33 \%)$ menyatakan tidak setuju, dan 5 (8,33\%) menyatakan sangat tidak setujuh, bahwa para tenaga kerja asing PT. VDNI yang ada di sekitar lingkar tambang tidak pernah bergaul dengan Publik setempat

Persepsi Publik terhadap pergaulan tenaga kerja asing di PT. Virtue Dragon Nickel Industri dapat dilihat pada Tabel 10.

Tabel 10. Persepsi Publik Terhadap Pergaulan Tenaga Kerja Asing di PT. Virtue Dragon Nickel Industri

\begin{tabular}{|c|l|c|c|}
\hline No. & \multicolumn{1}{|c|}{ Tingkat Persepsi Publik } & Jumlah (orang) & Persentase (\%) \\
\hline 1. & Sangat Baik & 1 & 1,67 \\
\hline 2. & Baik & 22 & 36,67 \\
\hline 3. & Kurang Baik & 32 & 53,33 \\
\hline 4. & Tidak Baik & 5 & 8,33 \\
\hline 5. & Sangat tidak Baik & - & - \\
\hline \multicolumn{2}{r}{ Jumlah } & $\mathbf{6 0}$ & 100 \\
\hline
\end{tabular}

Sumber: Data primer diolah (2018)

Sebagian besar responden menyatakan tenaga kerja asing yang bekerja di PT. VDNI memiliki pergaulan yang kurang baik. Hal ini dibuktikan bahwa sebanyak 32 (53,33\%) responden menyatakan memiliki pergaulan yang kurang baik, sebanyak $22(36,67 \%)$ memiliki pergaulan yang baik, sebanyak $5(8,33 \%)$ memiliki pergaulan yang tidak baik dan $1(1,67 \%)$ menyatakan memiliki pergaulan yang sangat baik.

\section{c. Persepsi Publik Terhadap Sikap Perilaku Tenaga Kerja Asing di PT. Virtue Dragon Nickel Industri}

Berdasarkan hasil penelitian yang dilakukan tentang persepsi Publik lingkar industri tambang terhadap sikap perilaku tenaga kerja asing di PT. VDNI yaitu :

1) Para tenaga kerja asing selalu bersifat ramah terhadap Publik di sekitar lingkar tambang, dapat dilihat pada Tabel 11.

Tabel 11. Persepsi Publik terhadap para tenaga kerja asing selalu bersifat ramah terhadap Publik di sekitar lingkar tambang

\begin{tabular}{clcc}
\hline No. & Tingkat Jawaban Responden & Jumlah (orang) & Persentase (\%) \\
\hline 1. & Sangat Setuju & 28 & 46,67 \\
\hline 2. & Setuju & 18 & 30,00 \\
\hline 3. & Ragu-ragu & 10 & 16,67 \\
\hline 4. & Tidak Setuju & 4 & 6,67 \\
\hline 5. & Sangat Tidak Setuju & - & - \\
\hline & Jumlah & $\mathbf{6 0}$ & $\mathbf{1 0 0}$ \\
\hline
\end{tabular}

Sumber: Data primer diolah (2018)

Berdasarkan Tabel 11. Sebanyak $28(46,67 \%)$ responden menyatakan sangat setujuh, sebanyak $18(30,00 \%)$ menyatakan setuju, sebanyak $10(16,67 \%)$ menyatakan ragu-ragu, sebanyak $4(6,67 \%)$ menyatakan tidak setuju, bahwa para tenaga kerja asing PT. VDNI bersifat ramah terhadap Publik di sekitar lingkar tambang

2) Para tenaga kerja asing sekitar lingkar tambang bersifat tertutup pada Publik setempat, dapat dilihat pada Tabel 12.

Tabel 12. Persepsi Publik terhadap para tenaga kerja asing sekitar lingkar tambang bersifat tertutup pada Publik setempat

\begin{tabular}{|c|l|c|c|}
\hline No. & Tingkat Jawaban Responden & Jumlah (orang) & Persentase (\%) \\
\hline 1. & Sangat Setuju & 28 & 46,67 \\
\hline 2. & Setuju & 18 & 30,00 \\
\hline 3. & Ragu-ragu & 10 & 16,67 \\
\hline 4. & Tidak Setuju & 4 & 6,67 \\
\hline 5. & Sangat Tidak Setuju & - & - \\
\hline \multicolumn{2}{|r|}{ Jumlah } & $\mathbf{6 0}$ & $\mathbf{1 0 0}$ \\
\hline
\end{tabular}

Sumber: Data primer diolah (2018) 
Vol 2 No 3 August-October 2019. pp. 1-8. Journal PUBLICUHO Faculty of Social and Political Sciences Halu Oleo University, Kendari, Southeast Sulawesi, Indonesia. ISSN 2621-1351 (online), ISSN 2685-0729 (print) Open Access at:

http://ojs.uho.ac.id/index.php/PUBLICUHO/index

Berdasarkan Tabel 12. sebanyak $28(46,67 \%)$ responden menyatakan sangat setuju, sebanyak $18(30,00 \%)$ menyatakan setuju, sebanyak $10(16,67 \%)$ menyatakan ragu-ragu, sebanyak 4 $(6,67 \%)$ menyatakan tidak setuju, bahwa para tenaga kerja asing PT. VDNI bersifat tertutup terhadap Publik setempat.

3)Para tenaga kerja asing disekitar lingkar tambang tidak berpengaruh pada budaya Publik setempat, dapat dilihat pada Tabel 13.

Tabel 13. Persepsi Publik terhadap para tenaga kerja asing disekitar lingkar tambang tidak berpengaruh pada budaya Publik setempat

\begin{tabular}{|c|l|c|c|}
\hline No. & Tingkat Jawaban Responden & Jumlah (orang) & Persentase (\%) \\
\hline 1. & Sangat Setuju & 28 & 46,67 \\
\hline 2. & Setuju & 18 & 30,00 \\
\hline 3. & Ragu-ragu & 10 & 16,67 \\
\hline 4. & Tidak Setuju & 4 & 6,67 \\
\hline 5. & Sangat Tidak Setuju & - & - \\
\hline \multicolumn{2}{r|}{ Jumlah } & $\mathbf{6 0}$ & $\mathbf{1 0 0}$ \\
\hline
\end{tabular}

Sumber: Data primer diolah (2018)

Berdasarkan Tabel 13. sebanyak $28(46,67 \%)$ responden menyatakan sangat setujuh, sebanyak $18(30,00 \%)$ menyatakan setuju, sebanyak $10(16,67 \%)$ menyatakan ragu-ragu, sebanyak $4(6,67 \%)$ menyatakan tidak setuju, bahwa para tenaga kerja asing PT. VDNI tidak berpengaruh pada budaya Publik setempat.

Persepsi Publik terhadap sikap perilaku tenaga kerja asing di PT. Virtue Dragon Nickel Industri dapat dilihat pada Tabel 14.

Tabel 14. Persepsi Publik Terhadap Sikap Perilaku Tenaga Kerja Asing di PT. Virtue Dragon Nickel Industri

\begin{tabular}{|c|l|c|c|}
\hline No. & \multicolumn{1}{|c|}{ Tingkat Persepsi Publik } & Jumlah (orang) & Persentase (\%) \\
\hline 1. & Sangat Baik & - & - \\
\hline 2. & Baik & 28 & 46,67 \\
\hline 3. & Kurang Baik & 32 & 53,33 \\
\hline 4. & Tidak Baik & - & - \\
\hline 5. & Sangat tidak Baik & - & - \\
\hline \multicolumn{2}{r}{ Jumlah } & $\mathbf{6 0}$ & 100 \\
\hline
\end{tabular}

Sumber: Data primer diolah (2018)

Sebagian besar responden menyatakan tenaga kerja asing yang bekerja di PT. Virtue Dragon Nickel Industri memiliki sikap perilaku yang kurang baik. Hal ini dibuktikan bahwa sebanyak 32 $(53,33 \%)$ responden menyatakan memiliki sikap perilaku yang kurang baik, sedangkan 28 $(46,67 \%)$ responden menyatakan memiliki sikap perilaku yang baik.

\section{KESIMPULAN}

Berdasarkan hasil dan pembahasan, kesimpulan dari penelitian ini adalah:

a. Persepsi Publik terhadap tenaga kerja asing Virtue Dragon Nickel Industri yaitu baik. Hal ini dibuktikan bahwa sebanyak $44(73,33 \%)$ responden menyatakan memiliki gaya hidup yang baik, sebanyak $15(25,00 \%)$ responden menyatakan memiliki gaya hidup yang kurang baik dan sebanyak $1(1,67 \%)$ responden menyatakan memiliki gaya hidup yang tidak baik.

b. Persepsi Publik terhadap pergaulan tenaga kerja asing PT. Virtue Dragon Nickel Industri yaitu kurang baik. Hal ini dibuktikan bahwa sebanyak $32(53,33 \%)$ responden menyatakan memiliki pergaulan yang kurang baik, sebanyak $22(36,67 \%)$ responden yang menyatakan memiliki pergaulan yang baik, sebanyak 5 (8,33\%) responden menyatakan memiliki pergaulan yang tidak baik dan $1(1,67 \%)$ responden menyatakan memiliki pergaulan yang sangat baik.

c. Persepsi Publik terhadap sikap perilaku tenaga kerja asing PT. Virtue Dragon Nickel Industri yaitu kurang baik. Hal ini dibuktikan bahwa sebanyak $32(53,33 \%)$ responden menyatakan kurang baik, sedangkan $28(46,67 \%)$ responden yang menjawab baik 


\section{SARAN}

Adapun saran yang disampaikan dalam hubungannya dengan penelitian ini adalah sebagai berikut:

1. Diharapkan kepada Pemerintah Kabupaten Konawe agar selalu mengawasi dan mengontrol kegiatan para pekerja tenaga kerja asing PT. Virtue di Industri di Kecamatan Morosi Kabupaten Konawe.

2. Pada aspek sosial diharapkan pada Publik Desa Morosi agar tetap mempertahankan hubungan antara pekerja tenaga kerja asing dalam menjaga sikap perilaku, pergaulan dan gaya hidup di sekitar lingkar industri pertambangan.

\section{DAFTAR PUSTAKA}

Dinas Tenaga Kerja dan Transmigrasi Provinsi Sulawesi Tenggara, 2018, Daftar Perusahaan pengguna TKA di Sultra. Kendari, Sulawesi Tenggara

Kementerian Energi dan Sumber Daya Mineral Republik Indonesia, 2018, 24 smelter telah beroperasi hingga akhir 2017, https://www.esdm.go.id/id/media-center/arsipberita/24-smelter-telah-beroperasi-hingga-akhir-2017. 20 oktober 2018

Muhammad Ali, 1985, penelitian kependidikan: prosedur dan strategi, Bandung : Angkasa

Rahman, Reza. 2009. Corporate Social Responsibilty: Antara Teori dan Kenyataan. Yogyakarta: Media Pressindo.

Rianse Usman dan Abdi. 2008, metodelogi penelitian sosial dan ekonomi, Bandung : Alfabeta

Sugiono, 2010, Statika untuk Penelitian, Edisi: November, Nomor II, Bandung: Alfabeta 